SlavVaria 1/2021. 65-75

DOI: $10.15170 /$ SV.1/2021.65

\author{
КАТАЛИН КРОО \\ (Будапешт, Венгрия)
}

\title{
«От автора» к читателю «Братьев Карамазовых» Тайна, чудо и авторитет - герменевтическая перспектива в предисловии романа
}

\begin{abstract}
Аннотация: Вступление к роману Ф.М. Достоевского «Братья Карамазовы», широко обсуждаемое в специальной литературе в разных своих аспектах, в настоящей статье изучается с новой точки зрения. Приводя в синтез выдающиеся критические достижения в толковании «От автора» в рамках исторического, нарратологического и риторического исследований, предлагаемый новый подход своеобразно выдвигает в центр внимания метапоэтический замысел предисловного текста. Освещаются формы семантизации трех основных тематических мотивов поэмы Ивана Карамазова «Великий инквизитор» (чудо, тайна и авторитет), из которых смыслопорождающим началом считается тайна (загадочность), контекстуализированная идеями познания и понимания. Анализируется внутренне противоречивый смысл выяснения пока не выяснившегося, мотивирующий развертывание сложного соотношения временных признаков пред и пост, начало и конец, а также формирующий определение значимости момента и процессуальности как моделированной жизни, так и дискурсивного творчества и его метапоэтической интерпретации.
\end{abstract}

Ключевые слова: Достоевский; Братья Карамазовы; предисловие «От автора»; мотивы тайна, чудо, авторитет; метапоэтика; время

Предисловие к последнему роману Ф.М. Достоевского под названием «От автора» уже не один раз привлекало к себе внимание, к тому же с разных точек зрения. Среди них, во-первых, выделяется подход, условно называемый «историческим», подвергающий толкованию генезис романа и планы его продолжения (RICE 2006, 2008; КАСАТКИНА 2019). О них четко говорится в исследуемом вступлении при утверждении, что автор должен пускаться в данные «весьма нелюбопытные и смутные объяснения», лишающие его возможности начать «просто-запросто без предисловий» (ДОСТОЕВСКИЙ 1976: 6 ${ }^{1}$. Как известно, проблема

\footnotetext{
${ }^{1}$ Далее в работе все цитаты приводятся по ДОСТОЕВСКИЙ 1976, из вступления к роману «От автора», С. 5 и 6. Выделения курсивом - если не отмечено иначе принадлежат автору статьи - K.К.
} 
заключается в том, что «жизнеописание одно», а романа получается два. Первый, к которому пишется вступление и действие которого разыгрывается за 13 лет до «теперешн $<$ его > текущ<его > момент $<\mathrm{a}>$ » автора (если под этим понимается биографический автор Достоевский в начале сериализации «Братьев Карамазовых» [TODD 1986: 695²], то указанный «момент» - 1879 г.), охватывает лишь «один момент из первой юности» героя, Алеши Карамазова. Тем не менее это первое произведение необходимо, так как без него был бы непонятен второй, истинно главный, современный автору роман. Предвиденное и предсказанное в предисловии продолжение жизнеописания Алеши, с названной исторической точки зрения, выясняет и интерпретирует содержание и формы упомянутых планов. Вторая точка зрения - нарратологическая (ВЕТЛОВСКАЯ 1977: 13-51, см. цит. ВАGBY 2016: 162). В новейших исследованиях она теснейшим образом сочетается с третьей, с перспективой риторической поэтики. Эти взаимосвязанные перспективы можно подвести к теоретической позиции, представляющей предисловие литературного произведения как часть рамочного комплекса, который Жерар Женетт (GENETTE 1982) определяет в качестве паратекста. Для объяснения введения «От автора» в свете нарратологического и риторического подходов, контекстуализированных пониманием паратекстуальных структур, мы будем останавливаться на чрезвычайно интересных и богатых интерпретациях Льюиса Бэгби и Ольги Юрьевны Ткаченко.

Бэгби интерпретирует предисловие как своебразно диалогизированный текст, в котором по признакам определенных дискурсивных вариантов (напр., употребление местоимений; прямая и несобственно-прямая речь [ср.: style indirect libre, erlebte Rede, narrated monologue, BAGBY 2016: 150]; логическая и эмоциональная структура и интонация и т. д.) вычерчиваются три нарративных субъекта (там же, 152): первый исторический образ Достоевского (биографический автор, реально пишущий вступительное слово к публикуемым в журнале частям своего романа); второй - литературная личина автора (BAGBY 2011: 244; implied author), которая возникает в результате нарративной ситуации (“an artifact of the narrative situation”, BAGBY 2016: 152) - его позиция, убеждения, разделяемая им система ценностей и его отношения к персонажам выясняются благодаря дискурсу, архитектонике текста и голосов литературных персонажей (там же, 153); а третий - рассказчик-биограф Алеши Карамазова, который будет вести повествование в самом романе, являясь намеренным продуктом исторического автора. Разные голоса, воплощаемые в дискурсивных вариантах, можно четко отделить друг от друга, они вступают во взаимоотношения. Художественная авторская личина

\footnotetext{
${ }^{2}$ Ср. более широкий контекст основных форм сериализации в разных культурах и в творчестве Достоевского: TODD 2014.
} 
(субъект, определяющий жанр фиктивного авторского предисловия) и рассказчик иногда противопоставлены, иногда соединяются в унисоне, в итоге в структуре, предоставляющей простор выражению и суммированию душевной и интеллектуальной диспозиции исторического Достоевского, за которым стоит другая, не фиктивная разновидность авторского предисловия. Суть диалога условного художественного автора (implied author) и рассказчика-биографа толкуется как взаимоотношение неопытного начинающего писателя, волнующегося из-за мнения своей читательской аудитории, и нарративного субъекта-мастера, опирающегося на свой опыт и знание и выступающего в роли ментора другого персонажа. Бэгби разбивает текст предисловия на единицы, в которых реконструируются указанный тип диалога и вторжение голоса самого Достоевского. Суть, однако, сводится не к самой аутентичности сегментирования (ученый сам допускает возможность иного толкования, отличающегося от его собственного, (там же, 160), а к выявлению феномена диалогической структуры предисловного дискурса. ${ }^{3}$ Драматизированная диалогическая форма аукториальных типов по сути дела порождает «виртуозную перформанцию нескольких голосов» (там же, 163).

О.Ю. Ткаченко рассматривает полифоническую композицию предисловия подчеркнуто с позиции риторической поэтики. На передний план выходит проблема «воздействия» многоголосого текста «на читателя и взаимодействия с ним» (TKAЧЕНКО 2019: URL) в духе предисловий, в жанровом плане берущих свое начало от древнерусской литературы, и функционирующих «как важнейший ресурс в установлении контактов с <..> читателями» (ibid., cit. из ЛАЗАРЕСКУ 2008: 47). Ткаченко указывает на гиперболизированное возвеличение встречной реплики публики, эффект «напряженного спора о едва начатом тексте, защиты его от сильного оппонента», вообще на «сложно риторико-аргументативн<ую> структуру» (см. в этом плане и модификацию сермоцинации). Различаются два уровня «риторической диалогизации повествования» - с одной стороны, «неполифоническое разноголосие неразделимого авторарассказчика и целого ряда критиков», а с другой стороны, двухголосый спор (с реальным читателем) - такая упорядоченность включает в себя как структуру «про и контра», так и появление структуры «унисона». Но, главное, упомянутое воздействие на читателя и вовлечение его в содействие с предисловным текстом как целым (как назначение жанровориторической поэтики предисловия) имеют цель подготовить реципиента к такому чтению следующего за предисловием романа, которое требуется, например, в процессе ознакомления его с поучениями Зосимы. Эти поучения воплощают художественное «слово, возведенное в четвертую

\footnotetext{
3 "The point, however, is that at least two voices operate at the surface level in the foreword” (BAGBY 2016: 160).
} 
степень: слово Зосимы, пересказанное Алешей, слово которого, в свою очередь, пересказывается рассказчиком, за которым стоит слово высшее, авторское» (ТKАЧЕНКО: URL).

Система сложной и многослойной конструкции голосов как идей, требующая понимания нарративных опосредований и, следовательно, поэтической ориентации на отсутствие непосредственности форм семантизации в романе, позволяет понять мотив загадочности. Он как вариант тайны толкуется не только в смысле нарративной игры или загадки, ${ }^{4}$ которую автор статьи отсылает к технике полифонического романа, где «почти нет слова без напряженной оглядки на чужое слово». Загадочность в целом романе, к чтению которого предисловие «приучает своего читателя», ${ }^{5}$ превращается в разные формы семантической загадки энигматичности поэтики. Ее самое наглядное воплощение проявляется на уровне тематизации гносеологических дилемм персонажей: Существует Бог или нет? По каким законам - человеческой натуры и спиритуальных ценностей - устроен мир? Можно ли принять миропорядок? Что такое этика? Как понимать относительность моральных принципов? Каково соотношение между идеалом и практикой? и т. д. и т. п. Композиция предисловия, таким образом, не ограничивается нарратологической или риторической структурой познания и реакциями на сведения, но также превосходит поэтическую область полифонического романа. Загадочность формулируется как идея. Она предвещает романный лейтмотив тайны, привлекающий к себе когнитивные и метафизические аспекты, связанные с человеческим мышлением и практической способностью объяснения эмпирических и трансцендентных онтологических вопросов рациональными аргументами. В то же время в данный идейный контекст рядом с тайной вносится и второй центральный мотив поэмы Ивана Карамазова «Великий инквизитор» - авторитет. Эта идея включает в себя вопрос нарративного авторитета (управляющей роли в отношении аутентичности, ср. ВЕТЛОВСКАЯ 1997: 68-1426 $)$ и вообще авторитетной авторской (аукториальной) фигуры в иерархии разных персонажных инкарнаций.

Возвращаясь к статье Ткаченко, следует выяснить указанный там второй и третий модусы полифонии, толкуемые как хронологический и пространственный. В первом случае имеется в виду «наложение

\footnotetext{
${ }^{4}$ О тайне в контексте детектива см. БОРОВСКИ 2008; о романе тайн см. БЕОГРАД 1987, 1988.

${ }^{5} \mathrm{O}$ роли «предисловного рассказа» как нарративного жанра в создании загадочности, противоречивости, несоответствий и недоумений, см. в работе: ЛИХАЧЕВ 1984.

${ }^{6}$ См. там: Понятие авторитетности (52-68); авторитетность и компрометация общих мнений (68-142).
} 
временных пластов», а во втором - «наложение художественного (текстового) и нехудожественного (затекстового, жизненного) пространств». Обе перспективы оцениваются с точки зрения влечения реального читателя, путем содействия с автором и его текстом (выражаясь иными словами, путем интенсивного участия реципиента в порождении текста и его толкования - речь идет о его герменевтическом и креативном действии в романе, в котором одной из ключевых проблем выступает проблема действующей любви). Одним источником временного наложения является соотношение между уже завершенным первым романом - и его предшествующим чтением по отношению к восприятию целого романа произведения - и ретроспективной перспективой, с которой писатель создает свой текст вступления. Совмещение «условно „авторского” и условно „читательского” времени» означает стирание границ между этими субъектами, подобно тому, как и «затекстовые» сведения (к ним относятся факты действительной жизни, общие суждения, сообщения, комментарии, «не характеризующие напрямую героя и композицию романа») могут объединить их (писателя и читателя) в общем и равноправно разделенном знании. Любопытно, что автор статьи к пространственному модусу причисляет общее суждение о странности и чудачестве героя, которое начинает определение с того, что эти черты $<\ldots>$ скорее вредят, чем дают право на внимание, особенно когда все стремятся к тому, чтобы объединить частности и найти хоть какойнибудь общий толк во всеобщей бестолочи. Чудак же в большинстве случаев частность и обособление.

Продолжим толкование данного сегмента, ведь он комментирует единственный «довольно» несомненный факт («Одно, пожалуй, довольно несомненно») характера Алеши: «это человек странный, даже чудак.» Тем не менее, именно сравнительная несомненность содержания данного утверждения релятивизируется затем в следующем противопоставленном сообщении: «Но странность и чудачество скорее вредят, чем <...>». Сообщение о странности и чудачестве героя является частью аргумента в пользу его примечательности, но эти черты с самого начала их приведения приобретают амбивалентность: «Для меня он примечателен, но решительно сомневаюсь, успею ли это доказать читателю». Повествователь совсем не уверен, успеет ли доказать примечательность своего героя. Так называемая затекстовая информация о том, как вредны могут быть указанные свойства, таким образом, на самом деле соответствует собственному сомнению повествователя. K тому же он уже в начале своего утверждения приводит ограничение: «Для меня он примечателен». Значит, он сомневается не только в своей способности объяснить черту примечательности литературного персонажа («решительно сомневаюсь, успею ли это доказать читателю»), но сомневается и в возможности общей оценки в отношении данного качества. Причина кроется в парадоксе: «Дело в том, что это, пожалуй, и деятель, но деятель 
неопределенный, невыяснившийся». Предполагается непонимание примечательности героя публикой, которой не предоставляется интеллектуальный опыт выяснившейся определенности характера литературного персонажа как деятеля. Но ведь не нужно удивляться недоверию читателя - повествователь «предвидит» именно то, что читатель «не увидит» доказательства правоты выбора Алеши в качестве героя (читатели не поймут его примечательности). Вместе с тем, «странно бы требовать в такое время, как наше, от людей ясности» - добавляет повествователь. В логическом построении хода мысли на самом деле происходят семантическое упорядочение и толкование мотивов, порождающих имплицитную тему загадочности/загадки. Повествователю нужно объяснить примечательность Алеши. Такой атрибут затем перевоплощается в тематический мотив значения: «насчет значения героя моего Алексея Федоровича», который рифмуется с мотивом толка. Он говорит о стремлении к тому, чтобы «найти хоть какой-нибудь общий толк во всеобщей бестолочи». Загадочность выбора, следовательно, требует объяснения значения, выяснения толка в бестолочи. Но парадокс в том, что нужно выяснить словами еще не выяснившийся характер самого Алеши и его деятельности. Повествователю предстоит определить текстом неопределенное. Иными словами, использованными в том же контексте в предисловии: он должен говорить о несомненном, в котором в то же время можно сомневаться, и больше всего можно сомневаться в возможности его выяснения. Отсюда вытекает еще новая формулировка противоречия: предвидение того («с прискорбием это предвижу»), что выяснения загадки никогда не смогут быть увидены.

Указанные процессы дают читателю понять, что смыслопорождение не остается в рамках нарратологической или риторической полифонической композиции романа. Общая семантика сводится к проблематизации познания и толкования, к постановке вопроса загадочности, тайны в герменевтическом смысле. По ходу разговора повествователя с читателем все больше и больше внимания сосредоточено на вопросе, как можно требовать от и для читателя ясности, когда он получает в романе неопределенный персонаж, еще не выяснившийся, и сам рассказчик в своем предисловии «предвидит», что хотя и читатель «прозорливый», он все же не «увидит» непосредственно значения героя, так как он сам должен выяснить невыяснившееся. Правда, повествователь в тематизированной форме к самому образу героя относит идею, что «странно бы требовать в такое время, как наше, от людей ясности», так объясняя естественность невыяснившейся природы (неопределенности) характера Алеши как деятеля. Тем не менее, сосредоточение на проблеме невозможности выяснения и вообще доминанта метаинформации повествовательной стратегии и читательского восприятия наглядно переустанавливают акцент на оправдание действия этих лиц, читателя и повествователя. Подчеркивается факт невозможности непосредственного ясного дискурса 
и соответствующего понимания. Неясность становится, таким образом, атрибутом текста - сначала как бы целостного романа, который и требует продолжения, второго романа, но в итоге самого предисловия в целом.

Неясность / загадочность как гносеологическая и дискурсивная тайна связана, с одной стороны, с чудачеством, происходящим в том числе и от неопределенности персонажа, а с другой, - с проблемой повествовательного / авторского / дискурсивного авторитета в качестве компетентности разъяснения и определения. Налицо метапоэтизация трех главных мотивов поэмы «Великий инквизитор» - чудо, тайна, авторитет с семантическим ядром тайны, загадочности. Три мотива составляют единство также путем их общей проекции на проблематику времени. $\mathrm{K}$ уже сказанному в данном отношении добавим, что наблюдаются две линии временного парадокса, векторы пред-пост и начало - конец. В первом случае речь идет не только об утверждении следующей за первым романом второй части жизнеописания Алеши, но и о системности мотивов предвидение (повествователь предвидит), предупреждение (он «заранее» предупреждает), прозорливость (см. этимологическую связь с предвидением: читатель «прозорливый»), предисловие и предлог (см.: «калька греч. про́ $\left.\varepsilon \varepsilon б \iota{ }^{7}\right)$ ), «первоначальное затруднение» повествователя. Все эти выражения осложняются и постепенно обрастают противоречиями, приобретая таким путем оттенки значения парадокса. Повествователь предвидит, что читатель не увидит, «почему он должен тратить время на изучение фактов его <Алеши> жизни», в то время как «прозорливый читатель уже давно угадал», что повествователь «с самого начала к тому клонил», что «<т>еряясь в разрешении сих вопросов, реш<ится> их обойти безо всякого разрешения», и даже этот читатель досадовал на него, зачем он «даром тра<тит> бесплодные слова и драгоценное время» - тут все же раскрывается догадка читателя о причине повествовательной стратегии, внушающей проблему решиться не разрешить поставленные вопросы. Повествователь, вырабатывая целостную систему противоречий в качестве семантической модели неясности (энигматичности, загадочности, таинственности / тайны), опять на первый взгляд парадоксальным образом, очень точно и ясно определяет мотивировку своего приема. На дилемму читателя, дважды представляемую через вопрос «зачем я даром трачу бесплодные слова и драгоценное время», он отвечает подчеркиванием точности своего сообщения («На это отвечу уже в точности»). В качестве второй причины траты слов и времени приводится объяснение, что таким путем повествователь «все-таки, дескать, заранее в чем-то предупредил». А такая новая неопределенность (в чем-то предупредил) в итоге подводит в конце предисловия к мысли, что читатели (и среди них критики) могут «дочитать до конца»

${ }^{7}$ ФАСMEP 1986-87: 3, 357. 
произведение или имеют право - как говорится: «законный предлог» бросить рассказ на первом эпизоде романа.

Парадокс пред-nocm, ${ }^{8}$ согласно указанной логике противоречий, приобретает кульминационную точку в смысловой проекции на временную ось начало - конец (см. дочитать до конца или только начать или прервать - произведение). А под произведением к концу предисловия могут пониматься или данный первый роман («бросить рассказ на первом эпизоде романа») или два рассказа / романа вместе (повествователь даже рад тому, что его роман «разбился сам собою на два рассказа „при существенном единстве целого”»). После того, как читатель познакомился с первым романом, он «сам определит: стоит ли ему приниматься за второй». Текстовая процессуальность в свете идеи от начала до конца внутри первого романа и в рамках двух произведений «при существенном единстве целого», однако, дополняется третьим контекстом, в котором понимается текстовая процессуальность самого предисловия. Ведь повествователь указывает, что он вел свою повествовательную стратегию с определенным намерением, которое характеризовало его «с самого начала» обращения к читателю («я с самого начала к тому клонил, что...»). Временное течение подчеркивается тем, что два раза принимается во внимание трата времени, толкуемая с читательской позиции. Конец предисловия тоже отмечен: «Ну вот и все предисловие». Предисловие, следовательно, тоже освещается с двух точек зрения, а его начало совпадает с началом романа: «Начиная жизнеописание героя моего <..>, нахожусь в некотором недоумении». Здесь берет свое начало осмысление предвидения повествователем неизбежных вопросов со стороны читателя по поводу выбора в качестве героя Алексея Карамазова, не великого, не известного персонажа. Очевидно, что начало первого романа, и в том числе предположенного целого жизнеописания, не отделяется от начала предисловия. Вступление «От автора» в этом свете толкуется как первая (предварительная) глава «Братьев Карамазовых».

Такая перспектива соотношения начала и конца снимает противоречие пред и пост, так как параллельно с сегментацией произведения на предисловие, на первый и второй роман приходит семантическое соединение не просто двух романов в идее единственного жизнеописания, но и самого предисловия и произведения об Алеше, чтение которого можно прекратить в любой момент (можно не только «бросить рассказ на первом эпизоде романа», но и «бросить книгу с двух страниц первого рассказа»). Возникает абстрактная семантическая модель трех текстов как единственного произведения, которое берет свое начало в общем пункте, в первом предложении предисловия. В нем в качестве главной

\footnotetext{
8 Толкование времени в «Братьях Карамазовых» в разных своих аспектах см. ТЮНЬКИН 1973.
} 
информации как бы выдвигается связь первого и второго романов жизнеописания Алеши. Тем не менее, по ходу чтения этого предисловия читатель раскрывает поэтический замысел текста (не ограничимый нарративным и риторическим построением) в определении общей дискурсивной стратегии произведения Достоевского, требующего толкования в настоящем времени. Происходит читательская интериоризация этой стратегии в плане возникновения интерпретационной позиции реципиента по отношению к единственному (существующему и симультанно, по ходу чтения толкуемому) роману «Братья Карамазовы».

В этом процессе предмет изображения (Алеша как «деятель неопределенный, невыяснившийся») получает осмысление не как характер литературного персонажа, разъясняемый в сумме некоторых качеств - как «великий», «замечательный» или «известный». Вместо этого сама проблема определяемости приводится в динамику в системе противоречий, в которой проблема выяснить невыяснившееся расслаивается в разных смысловых направлениях, проецируясь на столкновение а) моделированного в литературе жизненного феномена (герой) и внетекстовой действительности (люди в наше время [«странно бы требовать в такое время, как наше, от людей ясности»], - внушается, что вообще нет и не будет «ясности»); б) элемента модели (неясный / неопределенный герой) и дискурсивного его воплощения (текст объяснения); в) дискурса, передающего несомненный факт, и дискурса, сомневающегося в себе (сомнения повествователя касательно того, способен ли он объяснить как бы несомненное, которое само оказывается амбивалентным).

В итоге а) жизнь как внетекстовая действительность, ее б) модель 8 литературе и в) дискурс, порождающий данную модель, входят в форме семантической абстракции в сферу метапоэтики, созданной в предисловии (см. синтез а, б, в), которая раскрывает парадоксальность своих внутренних противоречий как загадочность (тайна) значения (в первую очередь героя, но как становится однозначным - и целостного дискурса). Мотив загодочности, как мы видим, включает в себя отсутствие непосредственно уловимого толка и присутствие парадоксального значения. В то же время доступность смысла связывается с процессуальностью развития дискурса от начала к концу (темпоральное состояние между пред и пост). Для приобретения характеристики читательского поведения дешифрирования загадочности предполагается пройти процесс, по ходу которого (благодаря содействию читателя с текстом) интегрируются разные этапы познания в пределах настоящего «момента» (см. когнитивный и дискурсивный аспект «момента»: «<..> роман второй - это деятельность моего героя уже в наше время, именно в наш теперешний текущий момент»; «Первый же роман <...> и есть почти не роман, а лишь один момент из первой юности моего героя») и синтезируется знание стиранием границ между началом и 
конщом, этапами пред и пост. Таким образом подводится субъект познания к суммированию полного текстового процесса - см.: «но вот и всё предисловие».

Процессуальность дискурса, с его способностью выяснить еще не выяснившееся, как форма доступа к [по]знанию, снимающая состояние «недо» (см. повествователя, который, «начиная жизнеописание своего героя», находится «в некотором недоумении»), соответствует порождению (дискурс) и толкованию (реципиент) значения, т. е. выяснению толка в бестолочи.

\section{Литература}

БОРОВСКИ М. (2008) Элементы детективного романа в структуре сюжета «Братьев Карамазовых» Ф.М. Достоевского // Достоевский и современность. Материалы XXII Международных Старорусских Чтений 2007 года, ред. В.В. Дудкин. Великий Новгород, 2008. 36-45.

ВЕТЛОВСКАЯ В.Е. (1977) Поэтика романа «Братья Карамазовы». Ленинград, 1977. 13-51.

ДОСТОЕВСКИЙ Ф.М. (1976) Братья Карамазовы: Роман в 4 ч. с эпилогом // Достоевский Ф.М. Полное собрание сочинений: В 30 тт. Т. 14. Ленинград, 1976.

КАСАТКИНА Т. (2019) Тайна «Братьев Карамазовых»: Алеша должен был стать революционером и убить царя? // ФОМА. Сентябрь 2019 (199) №9. https://foma.ru/tajna-bratev-karamazovyh-alesha-dolzhen-byl-statrevolyuczionerom-i-ubit-czarya.html (15.05.2021)

ЛАЗАРЕСКУ О.Г. (2008) Литературное предисловие: вопросы истории и поэтики (на материале русской литературы XVIII-XIX вв.). Автореферат дис. доктора филологических наук: 10.01.01. Москва, 2008.

ЛИХАЧЕВ Д.С. (1984) «Предисловный рассказ» Достоевского // Лихачев Д.С. Литература-реальность-литература. Ленинград, 1984. 96-103.

TКАЧЕНКО О.Ю. (2019) Риторическая полифония текста авторского предисловия в романе Ф. М. Достоевского «Братья Карамазовы» // Litera, 2019, № 1. 207-214. DOI: 10.25136/2409-8698.2019.1.28806

ТЮНЬКИН К.И. (1973) Крах карамазовского семейства. Предисловие // Достоевский Ф.М. Братья Карамазовы. Роман в четырех частях с эпилогом. Москва, 1973. 5-32.

ФАСМЕР М. (1986-87) Этимологический словарь русского языка. Т. 1-4. Москва, 1986-87.

BAGBY L. (2011) "Brief and Lame”: The Introduction to Dostoevsky's “The Brothers Karamazov”. The Slavic and East European Journal, 2011. Vol. 55, №. 2. 229-244.

BAGBY L. (2016) First Words. On Dostoevsky’s Introductions. Boston, 2016. DOI: 10.2307/j.ctt1zxsift

BEOGRAD M.J. (1987) Техника романа тайн в Братьях Карамазовых. Dostoevsky Studies. Vol. 8, 1987. 46-72.

BEOGRAD M.J. (1988) Техника романа тайн в Братьях Карамазовых. Dostoevsky Studies. Vol. 9, 1988. 10-32. 
GENETTE G. (1982) Palimpsestes. La littérature au second degré. Paris, 1982.

RICE J.L. (2006) Dostoevsky's Endgame: the Projected Sequel to the "Brothers Karamazov”. Russian History. 2008. Vol. 33, №. 1. 45-62. DOI: $\underline{10.1163 / 187633106 X 00032}$

RICE J.L. (2008) Foreshadowing of the Karamazov Sequel. Russian History, 2008, Vol 35, №. 1/2. 157-164. DOI: 10.1163/187633108X00238

TODD III W.M. (1986) The Brothers Karamazov and the Poetics of Serial Publication. Dostoevsky Studies, 1986. Vol. 7. 87-97.

TODD III W.M. (2014) “To be Continued”: Dostoevsky's Evolving Poetics of Serialized Publication. Dostoevsky Studies, New Series, 2014. Vol. 17. 23-33.

"From the Author" to the Reader of The Brothers Karamazov. Mystery, Miracle and Authority - Hermeneutic Perspectives in the Preface to the Novel. The paper offers new aspects to the critical reading of the widely interpreted preface "From the Author" in Dostoevsky's novel The Brothers Karamazov. Giving a synthesis of the historical, narratological and rethorical perspectives in the interpretation of the given text, this new approach enters a systematic metapoetic explanation. The semantic units examined lead to the triple motif construction, familiar from "The Grand Inqusitor" - mystery, miracle and authority. It is mystery that stands at the focus of the examination within the problem context of cognition, understanding, interpretation. The internally contradictory idea of elucidating something which is still unclear is projected upon such time concepts as pred - post, beginning - end, the actual moment and processuality. These motifs make reference both to the modelled reality and the modelling literary discourse, metapoetically setting a reading strategy for the recipient.

Keywords: Dostoevsky; The Brothers Karamazov; preface: "From the Author"; motifs of mystery, miracle and authority; metapoetics; time 